\title{
The Important Role of Collective Leadership in the Face of Change: Literature Review
}

\author{
Faris Alsaedi \\ Human Resource Management, King Abdulaziz University, Rabigh, Saudi Arabia \\ Email: fkvsfk@gmail.com
}

How to cite this paper: Alsaedi, F. (2022). The Important Role of Collective Leadership in the Face of Change: Literature $\mathrm{Re}$ view. Open Journal of Leadership, 11, 1-12. https://doi.org/10.4236/ojl.2022.111001

Received: January 6, 2022

Accepted: February 11, 2022

Published: February 14, 2022

Copyright (c) 2022 by author(s) and Scientific Research Publishing Inc. This work is licensed under the Creative Commons Attribution International License (CC BY 4.0).

http://creativecommons.org/licenses/by/4.0/

\begin{abstract}
Many organizations have considered different leadership styles to ensure effective operations. The most pronounced style of these leadership styles involves collective leadership. This leadership style involves accentuation of power distribution among different entities within a firm. The leadership style aggregates individual talents, expertise, and strengths to impact change. Various forms of this leadership style exist, including decentralization and density, and concentration. Collective leadership involves leaders assuming several roles. These roles include mentoring, organizing, problem-solving and motivating. These responsibilities make collective leadership very popular in modern organizations because they often have an accentuated need for motivation and employee morale. Modern organizations have also embraced technology as a tool for growth and competition. Successful implementation and maintenance of new technologies require collaboration. This situation makes collective leadership the most suitable leadership style for keeping pace with emerging technologies. Organizations' members should have social consciousness for modern organizations to remain relevant amid significant technological evolution that is taking place. Self-awareness and collective leadership have an intrinsic link that makes it vital for modern organizations to embrace it to keep pace with changing social consciousness. This change is also causing a considerable shift in customer expectations and requirements. Modern organizations have solved this complexity by promoting togetherness and accommodating varying viewpoints through collective leadership. The distributed influence in collective leadership is also leading to the pooling of unique skills and expertise, which is in turn, creating a more reliable framework for modern companies to engage with their customers. The changes in society mean that the workforce in modern firms is also evolving. This situation requires modern organizations to build the organizational culture that reflects the conscious nature of employees' needs and respects the existing communication channels. Such culture emanates through collective leadership. External stakeholders are also members of
\end{abstract}


the rapidly changing society. Modern firms have ensured harmony between internal stakeholders such as employees and external stakeholders such as investors through collective leadership. This process ensures that the company's actions and decisions reflect the will of the internal and external stakeholders. Consequently, collective leadership ensures that each person affiliated with an organization is heard and their opinions considered in decision-making hence achieving equity and inclusivity.

\section{Keywords}

Collective Leadership, Decentralization, Modern Organizations, Technology, Social Consciousness

\section{Introduction}

In a bid to ensure effective operations at the organizational level, many firms across the world have considered different leadership types. Several organizations have inculcated collective leadership forms as central elements in their organizational structure and culture with the promise of optimal results. Because of the collective leadership's inherent nature, it offers significant positive contributions to the nature and magnitude of change in modern organizations.

This literature review focuses on the importance of collective leadership in the modern organizational setting. The literature review takes a keen interest in the points related to rapid change like technology and the relationship between firms and various stakeholders. The literature review section is divided into various subsections: 1) the definition of terms and the background of this general review; 2) leadership roles under collective leadership; 3) collective leadership in modern organizations; 4) collective leadership and technology; 5) collective leadership and social consciousness; 6) collective leadership and employees; 7) collective leadership and customer expectations; 8) collective leadership and external stakeholders; 9) collective leadership and equity/inclusivity. The final section provides a summary of the literature review and the limitations of this study.

\section{Definition of Terms and Background}

Contractor et al. (2012) define collective leadership as a leadership process that accentuates power distribution among different entities within a firm. Collective leadership incorporates different people within an organization and relies on the aggregate of individual strengths, talents, skills, and expertise to influence change (Small \& Rentsch, 2011). On the other hand, Gronn (2002) asserts that leadership in collective leadership can be defined as "the status ascribed to one individual, an aggregate of separate individuals, sets of small numbers of individuals acting in concert or larger plural-member organizational units" (p. 428). Therefore, the basic definition of collective leadership accentuates team values and the development of knowledge and skills based on the aggregate elements. 
There are several collective leadership forms. One of the necessary collective leadership forms to consider is decentralization. Meindl, Mayo, \& Pastor (2002) assert that decentralization and density are essential elements in distinguishing between different forms of collective leadership. According to Meindl et al. (2002), decentralization in collective leadership alludes to the leadership influence by various organization members. On the other hand, density refers to the concentration of leadership influence (Meindl et al., 2002). Contractor et al. (2012) asserts that using the elements of concentration and density described above, the following collective leadership forms can be identified: 1) leader-centered; 2) distributed; 3) distributed-coordinated; and 4) distributed fragmented. Therefore, the fundamental topology of collective leadership can be mapped out following the variables of concentration and density.

\section{Leadership Roles under Collective Leadership}

Leadership generally has several functions in every setting. One of the common core aspects when examining leadership is that leadership roles are ephemeral, and they often change in different leadership settings. Contractor et al. (2012) asserts that collective leadership's unique trait allows various entities to optimize their best traits and develop knowledge and skills geared towards the best value for the organization. However, it is essential to note that collective leadership borrows from other leadership styles, types, and forms.

Meindl et al. (2002) use a transactional and transformational leadership framework to assess collective leadership use in organizations where motivation, organization, problem-solving behavior, and mentorship are essential elements. Meindl et al. (2002) assert that collective leadership should be used in symphony with transacttional and transformational leadership types. Therefore, according to this book, leadership roles in collective leadership are not dissimilar from other leadership types but are reinforced with the distributed and shared nature of power within the "teams", generally referring to the employees within the firms that choose collective leadership.

Mehra et al. (2006) use a social network analysis to examine distributed leadership in work teams. According to Mehra et al. (2006), distributed leadership roles associated with collective leadership are the basis for expectations of leadership set for the formal organization. Therefore, the social network analysis in this paper does not declare a standard dichotomy between leadership roles in collective leadership forms and leadership roles in other leadership forms.

\section{Collective Leadership in Modern Organizations}

Collective and distributed leadership are relatively new terms in leadership and organizational settings. Modern organizations often implement various leadership elements associated with their intended goals and objectives. Farazmand (2002) describes various characteristics of modern organizations, including the accentuated need for motivation and employee morale. Additionally, modern organi- 
zations will often have more employees because of specialization in certain tasks and functional organizational hierarchies (Farazmand, 2002). This assertion means that modern organizations must reflect leadership elements congruent with the need for optimization, a respect for the innate organizational culture, and the ability for quick adaptations and flexibility (Willmott, 1993). Therefore, modern organizations have several unique needs that distinguish them from traditional ones.

Collective leadership directly impacts the organizational culture in modern organizations. Azeem \& Mataruna (2019) use the Dubai School Inspection Board to view the cultural factors that might affect non-performing educational institutions. Consequently, Azeem \& Mataruna (2019) find that institutions that encompass collective leadership elements in their managerial approach have better success achieving their strategic goals and more potential to achieve sustainability. Similarly, Brookes (2015) asserts that a self-less leader is able to take advantage of the collaborative nature of collective leadership and harness the trust and norms necessary to achieve success. Therefore, collaborative leadership has the potential to gravitate modern organizations towards success and sustainability.

\section{Collective Leadership and Technology}

One of the key characteristics of modern organizations listed above is optimization. Raelin (2018) asserts that even though collective leadership has sometimes received criticism by certain circles claiming it invokes disputes, it bears one of the biggest promises towards optimization. Raelin (2018) argues that the modern organizational setting necessitates the contributions of the various stakeholders and multiple agents. Raelin (2018) asserts that collective leadership enables a dynamic concentration of power in various entities and management circles to ensure that knowledge, ideas, and actions are free-flowing and within a collaborative system.

Cullen, Willburn, Chrobot-Mason, \& Palus (2014) argue that for firms to implement collective leadership for technology optimally requires various sets of conscious and deliberate actions. One of the conscious and deliberate actions necessary for implementing collective leadership includes maintaining an open mind for diverse viewpoints (Cullen et al., 2014). Therefore, a healthy organizational culture that reflects the values of openness and transparency, especially when dealing with new approaches to existing issues, is necessary for the efficient implementation of collective leadership.

The interaction between collective leadership and technology is incomplete without considering the inherent challenges that may arise from technology implementation. Galliers \& Leidner (2014), in their book Strategic Information Management, assert that most technology and information systems do not fail because of issues with the technology or the systems rather because of the rigors in the implementation process. The organizational and management processes must be 
conscious of some of the inherent challenges associated with technology implementation, like distrust and conflicts with existing systems (Galliers \& Leidner, 2014; Carroll \& Teo, 1996). On the other hand, Galliers \& Leidner (2014) assert that organizational and management processes can sometimes aggravate the issues associated with technological implementation, for example, through excessive protocols, poor procurement systems, and less social consciousness. According to Galliers \& Leidner (2014), some of the factors to consider when deciding on implementing the new technology include the rate of centralization or decentralization in the organization and the technological differences between the new and existing and the control level for the various technologies. Therefore, the challenges in technology implementation offer a foundation for understanding the quintessential value of collective leadership in the modern organizational setting.

Owen \& Demb (2004) use the case of higher education institutions to assess the leadership strategies that are most compelling in the pace of change associated with technology. Leadership strategies that support proper technology implementation include understanding fundamentals, forging strategies, supporting innovation, communicating the firm vision and goals, and celebrating success. These leadership strategies are congruent with Meindl et al. (2002) in terms of the intricate features in collective leadership. Therefore, collective leadership can assist in the easy and efficient implementation of technology within the organization.

\section{Collective Leadership and Social Consciousness}

Collective leadership is intrinsically tied with social consciousness at an organization. Cooley \& Rieff (2017) define social consciousness as the collective selfawareness associated with particular units of people. According to Cooley \& Rieff (2017), a good example of social consciousness is class consciousness, ubiquitous in the workplace. According to Cooley \& Rieff (2017), social consciousness is innately linked with a deep understanding of human interdependence and the various values that underlie such understanding. Therefore, the definition of collective leadership as a managerial process that accentuates distributed power and influence is directly associated with social consciousness.

Pandey \& Gupta (2008) argue that there are two essential dimensions of reality that are considered for every reality: 1) the individual-collective dimension and 2) the interior-exterior dimension. The interior-exterior dimension encompasses the relationship between the intangible world of subjective experience and the objective world of objective behavior (Pandey \& Gupta, 2008). On the other hand, the individual-collective dimension refers to the relationship between the individual world of self-agency and the collective world of social communion (Pandey \& Gupta, 2008). One of the essential bearings for understanding social consciousness is the view of the inter-subjective realm (Pandey \& Gupta, 2008). According to Pandey \& Gupta (2008), this view is reminiscent of Emile Durkheim's 
thoughts on individual desires and how external social forces shape them. An integral part of operations in the organizational setting is how organizations are conscious of various elements. Pandey \& Gupta (2008) assert that "organizations may primarily operate at market consciousness societal consciousness or spiritual consciousness" (p. 892).

Therefore, there is a clear subjective and objective split between whatever view (atomist and integrative) on which a firm chooses to operate. Because such a decision is a management and administrative decision, business organizations' choice is determined by the potential of success. Collective leadership offers the opportunity for collective awareness that cuts across the inter-subjective realm described above. Therefore, social consciousness associated with a change in modern organizations can be affected by implementing collective leadership.

\section{Collective Leadership and Customer Expectations}

Customer expectations can sometimes lead to change. Customers generally expect organizations to change according to their changing trends, fashions, and tastes in products. Rust, Inman, Jia, \& Zahorik (1999) assert that customer satisfaction is largely a construct that considers an organization's efforts to cater to customer expectations. Almsalam (2014) asserts that in a study on five banks in Damascus, Syria, customer expectations and perceived service quality have a direct and positive relationship with customer expectations. However, Rust et al. (1999) assert that customer expectations are predominantly ephemeral, changing due to various factors, including time. Therefore, organizations must make conscious and deliberate efforts to suit the changing customer expectations.

Collective leadership offers a reliable trajectory for organizations to change based on changes in customer expectations. Friedrich et al. (2009) assert that distributed influence in collective leadership leads to the pooling of unique skills and expertise, which creates a more reliable framework for firms to interact with their customers. These sentiments are congruent with Mehra et al. (2006) in asserting that collective leadership exists and thrives within a network and is aided by distributive team leadership that relies on effective information exchange between the various stakeholders in a firm. Therefore, collective leadership contains the intrinsic tools that enable organizations to create a sufficient framework to understand consumer expectations.

Organizational change in the perspective of consumer behavior is also associated with technology. As indicated above, the pace of change in terms of technology can be positively affected by the willingness of a firm to adopt and operationalize the precepts of collective leadership. However, Bradley \& McDonald (2011) add to this point by arguing that social media and other forms of technology are critical features in ensuring that a firm attains a viable relationship with its consumers. Social and digital media have enabled firms to form and develop direct relationships with consumers. Therefore, adapting to the pace of change in the market through technology bears a positive correlation with the capacity for firms to cre- 
ate a lasting relationship with consumers that can allow sufficient information exchange.

\section{Collective Leadership and Employees}

Any form of leadership must consider the impact of employee relations within the firm. A healthy organizational culture must reflect a conscious nature for employees' grievances and proper respect for information channels. Collective leadership's primary benefits are not removed from the essence of employees.

Boone \& Hendricks (2009) assessed collaborative behaviors in the workplace and their relationship with effective information exchange and efficient decision-making. Boone \& Hendricks (2009) assert that the decentralized power and influence critical of collective leadership is directly related to functional diversity in an organizational setting. According to Boone \& Hendricks (2009), there is a direct link between employees' performance and the functional diversity and the varied expertise elucidated by the top management team. The benefits of diverse expertise include improved collaborative behaviors (Boone \& Hendricks, 2009). Therefore, collective leadership can positively impact change by providing a functional basis for employees that accentuates diversity in skill allocation, aiding effective information exchange and efficient decision making.

Carmeli \& Schaubroeck (2006) also conducted a study on the impact of multiple leaders and behavioral integration on the success of a particular leadership form. According to Carmeli \& Schaubroeck (2006), the study demonstrated that multiple leaders are insufficient for a firm to reap the benefits of diverse expertise. On the other hand, Carmeli \& Schaubroeck (2006) argue that collective leadership's most compelling trait is the capacity for effective information exchange because this is the only way to enhance team performance sufficiently and reap the benefits of diverse expertise. Therefore, when evaluating the ability for collective leadership to impact the pace of change, it is essential to consider the ability of this leadership framework to accentuate the positive elements associated with diverse expertise, team effort, and the integration of the various elements.

It is essential to consider that inherent barriers to team performance are associated with a particular baseline path and the way a group is structured and maintained. Even though the literature above has suggested that collective leadership is directly related to employee performance and can influence positive output from the diversity of expertise, it is essential to consider the role of the leader. Friedrich et al. (2009) assert that a leader's skills and abilities within collective leadership can affect team performance. According to Balkundi \& Kilduff (2005), a leader's skills and abilities are directly related to how they interact with their network. On the other hand, Boies \& Howell (2006) assert that a leader must note how communication takes place and how it affects the various employees because such is directly related to how collective leadership emerges if it does. Therefore, collective leadership in the modern setting needs to be recognized as a deliberate and 
conscious effort that affects the specific elements associated with employee satisfaction.

Finally, the importance of collective leadership in affecting the pace of change in modern institutions reflects the pace of group restructuring. According to Boies \& Howell (2006), a leader under collective leadership reserves the right and ability to structure the group by directly influencing the strategies and employees' behaviors towards an intended outcome. Some of the inherent advantages of collective leadership that may affect an organization's outcome include the decentralized power and the pooled skills and abilities under diversity of expertise. However, a leader's direction is quintessential in ensuring that the organization achieves optimal results congruent with particular goals. Therefore, collective leadership spearheaded by a leader with proper structuring strategies is essential in influencing a particular organizations' workforce towards specific positive change.

\section{Collective Leadership and External Stakeholders}

Most organizations have a diverse amount of stakeholders. Such stakeholders include the management, customers, employees, shareholders, and suppliers. External stakeholders, in this case, involve the customers, shareholders, suppliers, and other entities that are not involved in the day-to-day running of the firm. Because the relationship between the firm and the customers is discussed above, this section will mostly concentrate on the relationship between an organization and the shareholder, suppliers, and creditors/debtors.

Collective leadership influences the relationship between firms and external stakeholders. Ni, Yan, \& Pounder (2018) use the collective leadership framework to assess how leaders in the school setting perceive their influence and how other stakeholders' influences are reflected in the same setting. This study is based on School and staffing data in the United States' public schools between 2007 and 2008 (Ni et al., 2018). This study finds that principals (leaders) perceive that they amass significant influence in key decisions and that other key stakeholders have a substantial influence on other decisions (Ni et al., 2018). These findings are congruent with the operation of collective leadership. Shared power between different entities is the beacon of collective leadership. Ni et al. (2018) assert that school leaders need not be a zero-sum game, where leaders' influence affects the influence of other stakeholders. A harmonious school environment with the potential of positive results relies on the shared power associated with various collective leadership elements (Ni et al., 2018; Bolden, Petrov, \& Gosling, 2008). Therefore, collective leadership maps out the potential for success by asserting that decision influence must accommodate the distributed and shared power with certain entities in an organization, including the external shareholders.

Pluralistic organizations require collective leadership more than any other organization. Denis, Lamothe, \& Langley (2001) assert that pluralistic organizations can be defined as structured bodies with decentralized and sharable powers where various stakeholders can assert their individual and divergent perspectives 
about particular issues. Raelin (2018) argues that one of the critical arguments against collective leadership is that it invokes chaos where different perspectives are tabled about a particular issue. Pluralistic organizations can sometimes be parastatal and other institutions of public interest. Collective leadership is effective in public institutions because it provides a framework for shared commitment towards certain goals and visions and effective use of public resources (Ospina, 2017). Change in public institutions is effected through well-laid-out managerial processes. Such change's optimal capability can be influenced by the proper implementation of the precepts of collective leadership because such precepts accentuate the need for diverse expertise and the pooling of different abilities and skills by the various stakeholders.

\section{Collective Leadership and Equity/Inclusivity}

Modern organizations are becoming increasingly conscious about socio-political variables related to equal opportunity, equal treatment, and inclusivity.

Kozleski \& Choi (2018) use the example of the school settings in the United States to prove the positive outcomes of inclusivity. Kozleski \& Choi (2018) assess two years of data from schools that have adopted a systems approach originating from the federal government that shows specific interest to special education students. According to Kozleski \& Choi (2018), without focusing on students needing extensive support from intellectual and development disabilities, there would be a critical fault in the United States education system. This case proves the need for collective leadership for equity and inclusivity because Kozleski \& Choi (2018) demonstrate how changes in school leadership practices to include distributed power/influence and the appreciation for diversity in expertise leads to better outcomes in inclusivity in schools.

A similar picture is painted by LeBlanc, Sonnenberg, King, \& Busari (2020), who assert that in the medical scene, a collective approach enabled institutions to enact more changes to inculcate the precepts of inclusive discipline. Raelin (2018) asserts that collective leadership has a keen interest in the innate differences associated with different people's social and economic backgrounds. However, collective leadership involves decentralizing power, diversity of expertise, and shared influence. Thus, collective leadership bears precepts congruent with the understanding of inclusivity. Ubuntu is one of the case studies that Burgess (2017) uses to create a similarity panel between innate socio-cultural elements and the situations at the workplace. Burgess (2017) asserts that Ubuntu is not dead and that organizations must replicate the collective elements contained in this ideology for optimal results. Therefore, the pace that an organization adopts towards achieving equity and inclusivity is dependent on the adoption of certain elements associated with collective leadership.

\section{Literature Review Summary}

The literature review above scopes information about the value of collective leadership to modern organizations. The literature has proved beyond doubt that col- 
lective leadership can positively affect the nature, trajectory, and pace of change in modern organizations. Even though some organizations still rely on traditional leadership methods like transformational and transactional leadership models, collective leadership combines the best qualities of past leadership forms and models to create an effective framework for effective change.

According to the literature, collective leadership can be defined as a leadership process that incorporates an aggregate of separate individuals within an organization. Collective leadership accentuates the need for shared and distributed power between all the members of a team or organization. In the organizational setting, the literature infers that collective leadership can affect the pace of change through affecting employee relations, stakeholder relations, customer expectations, and technology implementation. Furthermore, collective leadership respects the socio-political basis for equal opportunity and treatment and bears precepts that can enable organizations to reach inclusivity. Therefore, the literature supports the assertion that collective leadership is important in the pace of positive change in modern organizations.

One limitation of this paper is that it relies on secondary research sources. Because of this reliance on such sources, some of the essential information is beyond the reach in this paper's bulk of knowledge. Nonetheless, the paper bears a significant foundation to understand the nature and practicality of collective leadership in an organizational setting. An additional limitation is that this paper could not commit to effective comparison sources for organizations that have achieved success throughout the years (traditional firms that survive in the modern settings) and how collective leadership may have morphed in such settings. Nonetheless, this paper contributes to the understanding of the various elements surrounding collective leadership, including a socio-political argument on how collective leadership impacts inclusivity. Therefore, the contributions made by this paper may be consequential for future research and future policy discussions.

\section{Conflicts of Interest}

The author declares no conflicts of interest regarding the publication of this paper.

\section{References}

Almsalam, S. (2014). The Effects of Customer Expectation and Perceived Service Quality on Customer Satisfaction. International Journal of Business and Management Invention, 3, 79-84.

Azeem, M., \& Mataruna, L. (2019). Identifying Factor Measuring Collective Leadership at Academic Workplaces. International Journal of Educational Management, 33, 1316-1335. https://doi.org/10.1108/IJEM-04-2018-0131

Balkundi, P., \& Kilduff, M. (2005). The Ties that Lead: A Social Network Approach to Leadership. The Leadership Quarterly, 16, 941-961. https://doi.org/10.1016/j.leaqua.2005.09.004

Boies, K., \& Howell, J. M. (2006). Leader-Member Exchange in Teams: An Examination 
of the Interaction between Relationship Differentiation and Mean LMX in Explaining Team-Level Outcomes. The Leadership Quarterly, 17, 246-257. https://doi.org/10.1016/j.leaqua.2006.02.004

Bolden, R., Petrov, G., \& Gosling, J. (2008). Developing Collective Leadership in Higher Education. Leadership Foundation for Higher Education.

Boone, C., \& Hendricks, W. (2009). Top Management Team Diversity and Firm Performance: Moderators of Functional Background and Locus-of-Control Diversity. Management Science, 55, 165-180. https://doi.org/10.1287/mnsc.1080.0899

Bradley, A. J., \& McDonald, M. P. (2011). The Social Organization: How to Use Social Media to Tap the Collective Genius of Your Customers and Employees. Harvard Business Press.

Brookes, S. (2015). The Selfless Leader: A Compass for Collective Leadership. Macmillan International Higher Education.

Burgess, G. J. (2017). Unpacking Inclusivity: Lessons from Ubuntu Leadership. In Boitano, A., (Ed.), Breaking the Zero-Sum Game (pp. 379-394). Emerald Publishing Limited. https://doi.org/10.1108/978-1-78743-185-020171035

Carmeli, A., \& Schaubroeck, J. (2006). Top Management Team Behavioral Integration, Decision Quality, and Organizational Decline. The Leadership Quarterly, 17, 441-453. https://doi.org/10.1016/j.leaqua.2006.06.001

Carroll, G. R., \& Teo, A. C. (1996). On Social Networks of Managers. Academy of Management Journal, 39, 421-440.

Contractor, N. S., DeChurch, L. A., Carson, J., Carter, D. R., \& Keegan, B. (2012). The Topology of Collective Leadership. The Leadership Quarterly, 23, 994-1011. https://doi.org/10.1016/j.leaqua.2012.10.010

Cooley, C. H., \& Rieff, P. (2017). Social Organization: A Study of the Larger Mind. New York: Routledge. https://doi.org/10.4324/9781315129655

Cullen, K., Willburn, P., Chrobot-Mason, D., \& Palus, C. (2014). Networks: How Collective Leadership Works (pp. 13-16). Greensboro, NC: Center for Creative Leadership.

Denis, J. L., Lamothe, L., \& Langley, A. (2001). The Dynamics of Collective Leadership and Strategic Change in Pluralistic Organizations. Academy of Management Journal, 44, 809-837. https://doi.org/10.5465/3069417

Farazmand, A. (2002). Modern Organizations: Theory and Practice. Greenwood Publishing Group.

Friedrich, T. L., Vessey, W. B., Schuelke, M. J., Ruark, G. A., \& Mumford, M. D. (2009). A Framework for Understanding Collective Leadership: The Selective Utilization of Leader and Team Expertise within Networks. The Leadership Quarterly, 20, 933-958. https://doi.org/10.1016/j.leaqua.2009.09.008

Galliers, R., \& Leidner, D. E. (2014). Strategic Information Management: Challenges and Strategies in Managing Information Systems. New York: Routledge. https://doi.org/10.4324/9781315880884

Gronn, P. (2002). Distributed Leadership as a Unit of Analysis. The Leadership Quarterly, 13, 423-451. https://doi.org/10.1016/S1048-9843(02)00120-0

Kozleski, E. B., \& Choi, J. H. (2018). Leadership for Equity and Inclusivity in Schools: The Cultural Work of Inclusive Schools. Inclusion, 6, 33-44.

https://doi.org/10.1352/2326-6988-6.1.33

LeBlanc, C., Sonnenberg, L. K., King, S., \& Busari, J. (2020). Medical Education Leadership: from Diversity to Inclusivity. GMS Journal for Medical Education, 37, 9 p.

Mehra, A., Smith, B. R., Dixon, A. L., \& Robertson, B. (2006). Distributed Leadership in 
Teams: The Network of Leadership Perceptions and Team Performance. The Leadership Quarterly, 17, 232-245. https://doi.org/10.1016/j.leaqua.2006.02.003

Meindl, J. R., Mayo, M., \& Pastor, J. C. (2002). Shared Leadership in Work Teams: A Social Network Approach. Instituto de Empresa.

Ni, Y. M., Yan, R., \& Pounder, D. (2018). Collective Leadership: Principals' Decision Influence and Other Stakeholders' Supportive or Inhibiting Decision Influence. Educational Administration Quarterly, 54, 216-248. https://doi.org/10.1177/0013161X17723427

Ospina, S. M. (2017). Collective Leadership and Context in Public Administration: Bridging Public Leadership Research and Leadership Studies. Public Administration Review, 77, 275-287. https://doi.org/10.1111/puar.12706

Owen, P. S., \& Demb, A. (2004). Change Dynamics and Leadership in Technology Implementation. The Journal of Higher Education, 75, 636-666. https://doi.org/10.1353/jhe.2004.0037

Pandey, A., \& Gupta, R. K. (2008). A Perspective of the Collective Consciousness of Business Organizations. Journal of Business Ethics, 80, 889-898.

https://doi.org/10.1007/s10551-007-9475-4

Raelin, J. A. (2018). What Are You Afraid of: Collective Leadership and Its Learning Implications. Management Learning, 49, 59-66. https://doi.org/10.1177/1350507617729974

Rust, R. T., Inman, J. J., Jia, J., \& Zahorik, A. (1999). What You Don't Know about CustomerPerceived Quality: The Role of Customer Expectation Distributions. Marketing Science, 18, 77-92. https://doi.org/10.1287/mksc.18.1.77

Small, E. E., \& Rentsch, J. R. (2011). Shared Leadership in Teams. Journal of Personnel Psychology, 9, 203-211.

Willmott, H. (1993). Strength Is Ignorance; Slavery Is Freedom: Managing Culture in Modern Organizations. Journal of Management Studies, 30, 515-552.

https://doi.org/10.1111/j.1467-6486.1993.tb00315.x 